\title{
THE RATIONAL INESCAPABILITY OF VALUE OBJECTIVISM
}

\section{T. J. Mawson}

Tim Mawson argues that moral values hold objectively.

Do you believe that all value is subjective? An increasing number of people would answer this question, yes. They'd report that they think that the system of values by which we order our lives isn't given to us by something that exists in some sense objectively, independently of our concerns. Rather, it is created by those concerns and, as such, relative to them. When society changes, so value changes. To consider an example from the realm of moral value: two hundred years ago, sex before marriage was morally bad in Great Britain; today it's morally neutral; maybe in a few years' time it will be obligatory. According to the Subjectivist about morality, what goes for the morality of sex before marriage goes for the morality of everything else too - the whole of it is a fabrication. And, according to the Subjectivist about all value, what goes for morality goes for all other sorts of value as well.

Against the Subjectivist view stands a more traditional one: Objectivism. According to the Objectivist, there is in some sense objective value. The Objectivist about moral value, for example, will insist that morality isn't simply a matter of how - subjectively - we feel about the world; it's a matter of how - objectively - the world ought to be. Of course people's opinions on moral matters change with time, but, according to the Objectivist about morality, morality itself does not change; if sex before marriage isn't in itself a bad thing, then people two hundred years ago who thought that it was were just wrong in what they thought and if today we think differently on this score, then it is we who are right.

I say that according to the Objectivist morality does not change; I should be more careful and say that according to the Objectivist it does not change fundamentally. Even the most hardcore Objectivist will admit that the demands of morality vary with the circumstances: if I'm about to leave a man's shop 
with something from his shelves in my hands, then it would be (at least prima facie) obligatory for me to pause at the cash desk to make payment; if I'm leaving his shop empty-handed, then no such moral obligation obtains even prima facie. But, whilst the Objectivist will allow that morality can in this way change with the circumstances, the Objectivist will insist that there are non-changing principles - in this case the principle that stealing is bad - that undergird such local variations in morality's demands. Stealing isn't just bad in Great Britain in today's culture; it's bad everywhere and always. Why? Because what makes it bad isn't an individual's or society's attitude towards it; it's a feature of stealing in itself.

It must be admitted that there is much contention within the Objectivist camp over what constitute examples of these objective values, but there is also much consensus. The badness of stealing would be an example over which there is minimal disagreement. That's why I chose it. Other non-contentious examples amongst Objectivists would be hypocrisy, cruelty, rape, promise-breaking, and lying being in themselves bad; and integrity, kindness, love, promise-keeping, and truth-telling being in themselves good. Objectivists about morality contend that the badness and goodness of these things isn't something that we've fabricated; it's more objective than that. Society may change in its attitudes towards these things, but there are parameters imposed by the fundamental principles on how societies are morally permitted to change. If a society were ever to develop that valued any of hypocrisy, cruelty, rape, promise-breaking, and/or lying, then that society would have developed in a way that it ought not to have developed. Of course it's difficult to imagine any society that valued these things holding itself together for long enough to constitute a society. But we can imagine as a realistic and perhaps historically-instantiated possibility a society that valued one or two of them. The people in such a society might feel approving towards, let's say, cruelty; might reward it with their laws and social conventions; and treat acts of kindness with the same sort of horror that we in our society treat acts of cruelty. But in doing all of this they would err. If a particular member of that 
society had been so brought up that it was now as inconceivable to him that he might be going wrong in valuing cruelty as it is to us that we might be going wrong in valuing kindness, then we should not blame him for his error - it's not his fault that he's made this mistake. But that we should not blame him for his error does not make it any less of an error - it is still a mistake.

In this paper l'm going to argue for the rational inescapability of Objectivism about at least some values; in other words, I'm going to argue that Subjectivism about all value is indefensible. I'm going to do this via a two-stage argument, the first stage being based on a thought experiment and some intuitions which the majority will have in response to it, the second stage being based on how those who don't share these intuitions must think about the fact that they don't if they are to think of themselves as rational. Here we go then with the thought experiment.

After the Second World War, many Nazis fled to South America. It is quite possible that some might have formed self-sufficient communities there in the jungles, preserving their Nazi culture down the generations until now there is a thriving Nazi society as yet to be discovered by the outside world. Let's suppose that this is indeed what has happened and that, whilst exploring with your friend, you wander deep into the territory of this society. You are walking along a road between two of their villages when you fall into conversation with a couple of their local policemen. All is going well, until you let it slip that your friend is Jewish. Suddenly, the two policemen jump on your friend and tell you that you must shoot him to death. You are given an opportunity to consult the society's legal codes, a copy of which one of the policemen carries with him. In doing so, you realise that your shooting your friend would be absolutely legal, indeed it is legally required of you. Being Jewish is an offence punishable by death by shooting and the law dictates that he or she who brings the existence of a Jewish person to the attention of the police has 'the honour' of being the executioner, an honour which he or she may not 
refuse. You ask whether anyone has ever challenged this law. The policemen look disgusted at the thought, telling you that nobody has; nobody has ever wanted to do so. So it is that this law which enjoys the unanimous and unreserved support of the local population allows no possibility for appeal against the sentence of death by shooting, a sentence which must be carried out immediately. The two policemen explain all of this to you. One of them enthusiastically presses his gun into your hands as the two of them hold your friend securely before you, pointing out parts of his body through which a passing bullet will most probably be fatal. The policemen look at you with a cheerful expectancy. Your friend looks at you too. He has quite different expectations from those of the policemen. What ought you to do?

Everyone sane knows what the wrong answer to this question is. The wrong answer is, 'Shoot your friend'. But by what standard is this the wrong answer? Not the standard that is actually enshrined in the legal codes of the society in which you've found yourselves and which enjoys the support of that society. That standard dictates that you shoot your friend. By your own, internal, standard then? But we all know that being good isn't simply a matter of doing what is in accord with one's own internal standard. We all acknowledge that individuals can go wrong in their moral assessment of actions. It seems, from our reaction to this example, that we think that a whole society can go wrong in its moral assessment of actions too. If this is indeed what we think, then we must be assuming that morality is independent, not only of anyone's beliefs or attitudes, but also of any society's beliefs and attitudes. Is it independent of everyone's beliefs and attitudes? It seems that we think it is, for we may imagine a possible world in which the Nazis had won the Second World War and so now the culture which in my thought experiment is confined to a corner of the jungles of South America has spread to all corners of the globe. And we think that even if we lived in a world where everyone believed that shooting someone merely for being Jewish was right, we'd all be wrong (although of course we wouldn't then realise it), just as we think that even if we lived 
in a world where the history of science had taken a different turn so that now everyone believed that the Earth was flat, we'd all be wrong about that (although again of course we wouldn't then realise it). It seems then that we do not believe in Subjectivism about all values; we endorse Objectivism about moral values.

That's the first stage of my argument and I hope it will have convinced most people reading it that they believe in Objectivism at least about moral value, but let me now suppose that you're unconvinced by the argument as l've presented it so far. If you take the fact that you're unconvinced as reflecting some sort of philosophical achievement on your part, you'll have to think not simply that as a psychological matter of fact you've remained unconvinced by it but that you're right to remain unconvinced. You'll have to think that this argument shouldn't convince one of the objectivity of value. But the sort of judgement you'll then be making itself supposes some normative principle or principles that dictate what one should or should not believe on the basis of a certain argument. So you'll be tacitly relying on the falsity of extreme Subjectivism about value when you judge of the merits or otherwise of any argument in favour of Objectivism (rather than merely the effects that considering that argument has as a matter of fact had on you). You'll be thinking that there are at least objective standards determining what people should believe as a result of arguments.

Of course, it is possible to retreat from Objectivism even here. Rather than saying of my argument thus far that it should not convince, one might simply report as a psychological fact about oneself that it has not convinced. Rather than saying that if you believe that $p$ and you believe that $p$ implies $q$, then you should believe that $q$, one might rest content with saying that one - or members of one's society - tend to believe that $q$ if they believe that $p$ and they believe that $p$ implies $q$. And so on. If one goes down this road, it is true that no-one will be able to give one any reason to return, but that is only true because one will have abandoned the harder path of advancing reasons for the having of one belief rather than another 
in favour of the easier path of merely observing what beliefs one (or one's society) actually has. The more philosophically defensible ('more' because at least capable in principle of being defended) path to tread on the issue of the objectivity of value accepts then that there are objective principles dictating how people should order their beliefs, but maintains that there aren't any such principles dictating how people should order their actions. Someone might say, 'There's objectivity in epistemic or noetic normativity, but there isn't any in moral normativity. When thinking, we should follow the law of noncontradiction (for example) because it is impossible for contradictories to both be true and it's good to believe truths and avoid believing falsehoods. However, when talking to others about one's thoughts, it's not the case that we shouldn't needlessly mislead them as it would have been had it been good to help them reach truths and avoid falsehoods.' 'But why?' one must ask of a defender of such a distinction.

Surely if it's good to believe the truth and avoid falsehood, it's good to avoid needlessly leading people away from truth and towards falsehood and thus it's always in itself bad to lie to people. The person initially walking the path sketched in the previous paragraph will, in the light of this, need to switch, it seems, to claiming that there are objective principles dictating what it is good and bad for himself or herself to believe, but there aren't any dictating what it is good and bad for others to believe; there's only epistemic or noetic normativity for him or her. Thus could he or she say, 'When thinking, I should follow the rules of logic because it's good for me to believe the truth and avoid falsehood.' without committing himself or herself to the more general claim that it's good to believe the truth and avoid falsehood, the more general claim from which it would follow that one has good reason to avoid needlessly lying to people. But he or she would now be left without any way of explaining why it is good for him or her and no-one else to believe truth and avoid falsehood. He or she wouldn't be able to explain why it is good for him or her to believe truth and avoid falsehood in terms of the more general fact that its good per se to believe truth and avoid falsehood and he or she wouldn't 
be able to consider himself or herself reasonable in thinking of himself or herself as a special case, the only person to whom such objective principles apply.

I suggest then that the rational inescapability of Objectivism for us qua Philosophers, in considering reasons for belief, will lead to Objectivism for us qua agents, in considering reasons for actions that will affect the beliefs of others; thus it will lead to Objectivism about at least some moral value. Objectivism about at least some value is inescapable for those reflective people who wish to believe rationally; Objectivism about moral value is inescapable for those reflective people who wish to act rationally. It is possible to argue that we wouldn't be people if we didn't wish to believe and act rationally, but to advance that argument would require another paper, so it is fortunate that in this context a less strong claim is sufficient to ensure my conclusion being binding on you who read this. Whilst not perhaps impossible, at least it is surely very unlikely that you, as a reader of Think, will not find as you introspect that you wish to believe and act rationally.

T. J. Mawson is Fellow and Tutor in Philosophy, St Peter's College, Oxford. 
